\title{
ВОЗМОЖНОСТИ ПРИМЕНЕНИЯ КОСМИЧЕСКИХ СНИМКОВ ВЫСОКОГО РАЗРЕШЕНИЯ ПРИ МОНИТОРИНГЕ ГОРОДСКИХ ТЕРРИТОРИЙ
}

\section{Марина Александровна Плотникова}

Сибирский государственный университет геосистем и технологий, 630108, Россия, г. Новосибирск, ул. Плахотного, 10, обучающийся, тел. (983)322-52-15, e-mail: Plotnikova-MA2018@sgugit.ru

\section{Елена Павловна Хлебникова}

Сибирский государственный университет геосистем и технологий, 630108, Россия, г. Новосибирск, ул. Плахотного, д. 10, доцент кафедры фотограмметрии и дистанционного зондирования, тел. (913)901-94-58, e-mail: e.p.hlebnikova@sgugit.ru

В статье рассмотрены особенности выявления изменений, происходящих на территории городского пространства в связи со строительством новых объектов, с помощью архивных спутниковых снимков высокого разрешения Sentinel-2. Применен алгоритм автоматизированного выявления изменений, основанный на использовании индексных изображений в программе ERDAS IMAGINE 2010. Выявлены дальнейшие перспективы мониторинга городских территорий по космическим снимкам.

Ключевые слова: мониторинг городских территорий, разновременные космические снимки, Sentinel-2A, автоматизированное дешифрирование

\section{POSSIBILITIES OF USING HIGH RESOLUTION SATELLITE IMAGES FOR MONITORING URBAN AREA}

\section{Marina A. Plotnikova}

Siberian State University of Geosystems and Technologies, 10, Plakhotnogo St., Novosibirsk, 630108, Russia, Student, phone: (983)322-52-15, e-mail: Plotnikova-MA2018@sgugit.ru

\section{Elena P. Khlebnikova}

Siberian State University of Geosystems and Technologies, 10, Plakhotnogo St., Novosibirsk, 630108, Russia, Associate Professor, Department of Photogrammetry and Remote Sensing, phone: (913)901-94-58, e-mail: e.p.hlebnikova@sgugit.ru

This article discusses the features of identifying changes occurring in urban areas in connection with the construction of new facilities using Sentinel-2 high-resolution archive satellite images. The algorithm for automated change detection based on the use of index images in the ERDAS IMAGINE 2010 program was applied. Further prospects for monitoring urban areas by satellite imagery were identified.

Keywords: monitoring of urban areas, multi-temporal space images, Sentinel-2A, automated interpretation

В условиях динамичного развития и роста городского пространства требуется постоянный мониторинг территорий, подверженных антропогенным изменениям. Особенно это актуально для крупных региональных центров и мегаполисов. Оперативность является ключевым фактором для решения задач по 
управлению и контролю за современным городом. Наибольшая оперативность достигается при использовании данных дистанционного зондирования Земли из космоса. Информация об изменениях может быть получена в результате сравнительного анализа разновременных космических снимков. На сегодняшний день разработано большое количество методов и алгоритмов автоматизированного обнаружения изменений по архивным спутниковым изображениям [1-5].

Для выявления динамики городской инфраструктуры необходимы высокие информативные свойства снимков, поэтому для данных задач целесообразно использовать космические снимки высокого пространственного разрешения.

В статье в качестве объекта исследования был выбран тематический парк развлечений «Остров мечты» в Москве, строительство которого началось в 2016 году [6].

Целью работы является исследование возможностей мониторинга городских территорий по снимкам высокого разрешения.

Для анализа выбранного объекта исследования, а именно определения временных рамок и идентификации произошедших изменений за данный период, был использован Интернет-ресурс Гугл планета Земля (GoogleEarth), в котором размещены спутниковые изображения всей земной поверхности.Данные архивные многозональные космические снимки представлены на рис. 1.

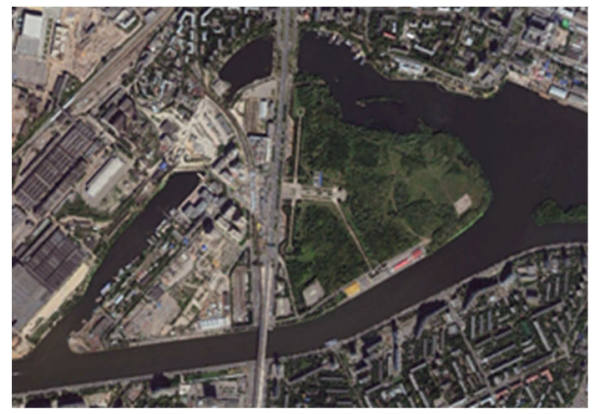

a)

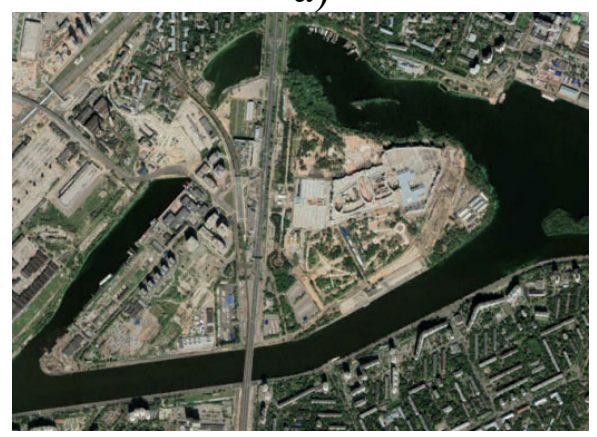

в)

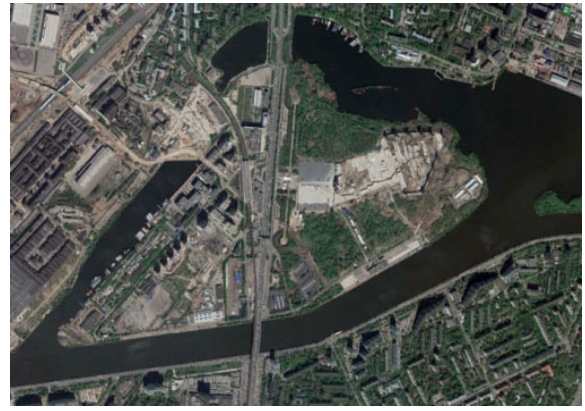

б)

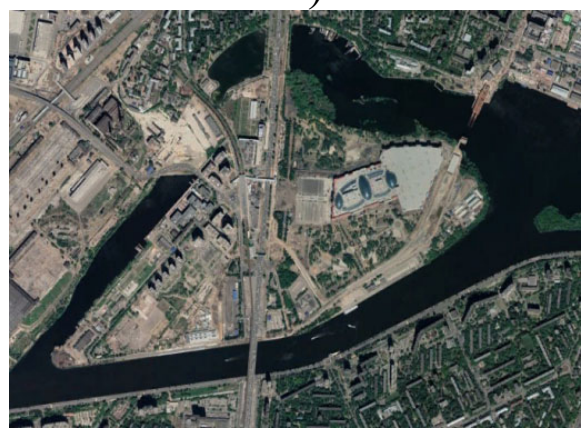

2)

Рис. 1. Этапы строительства парка развлечений «Остров мечты»:

а) 21.08 .2015 ; б) 15.05 .2017 ; в) 19.08.2018; г) 04.06.2019

При выборе космической съемочной системы для мониторинга городских территорий в первую очередь необходимо учитывать пространственное разрешение. На сегодняшний день в свободном доступе для научно- 
исследовательских задач можно получить архивные спутниковые снимки Sentinel-2 с высоким пространственным разрешением (10 м).

Кроме характеристик космических съемочных систем при мониторинге также необходимо учитывать сезон съемки и наличие облачности. Облачность закрывает интересующие объекты и делает невозможным наблюдение в оптическом диапазоне. Также важным при организации мониторинга является время года съемки. Очевидно, что снимки, полученные в зимний период, будут содержать меньше информации, так как снежный покров скрывает контуры многих объектов.

Учитывая выше перечисленные характеристики в качестве исходных материалов для исследования были получены архивные спутниковые снимки Sentinel-2 на даты 18.09.2015 и 28.08.2019 с помощью ресурса Геологической службы США (USGS).

Спутники серии Sentinel-2 оснащены оптико-электронным мультиспектральным сенсором для съемок с разрешением от 10 до 60 м в видимой, ближней инфракрасной (VNIR) и коротковолновой инфракрасной (SWIR) зонах спектра, включающих в себя 13 спектральных каналов (443-2190 нм), каналы представлены в таблице [7].

Спектральные каналы Sentinel-2

\begin{tabular}{|c|c|c|}
\hline Номер канала & Название канала & $\begin{array}{c}\text { Пространственное раз- } \\
\text { решение (м) }\end{array}$ \\
\hline 1 & Coastalaerosol & 60 \\
\hline 2 & Blue & 10 \\
\hline 3 & Green & 10 \\
\hline 4 & Red & 10 \\
\hline 5 & Vegetationrededge & 20 \\
\hline 6 & Vegetationrededge & 20 \\
\hline 7 & Vegetationrededge & 10 \\
\hline 8 & NIR & 20 \\
\hline $8 \mathrm{a}$ & Narrow NIR & 60 \\
\hline 9 & Watervapour & 60 \\
\hline 10 & SWIR - Cirrus & 20 \\
\hline 11 & SWIR & 20 \\
\hline 12 & SWIR & \\
\hline
\end{tabular}

В работе были использованы только каналы 2, 3, 4 видимой (RGB) и канал 8 ближней инфракрасной зоны спектра.

В программном комплексе ERDAS IMAGINE произведен импорт и объединение каналов в один многослойный снимок. Данная процедура проводилась с помощью инструмента LayerStacking. На рис. 2 представлены снимки Sentinel2 на разные даты в «натуральных» цветах. 


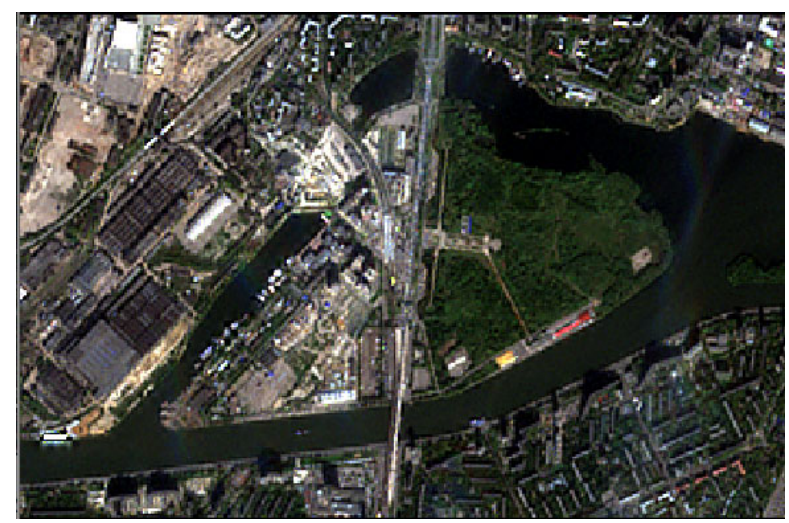

a)

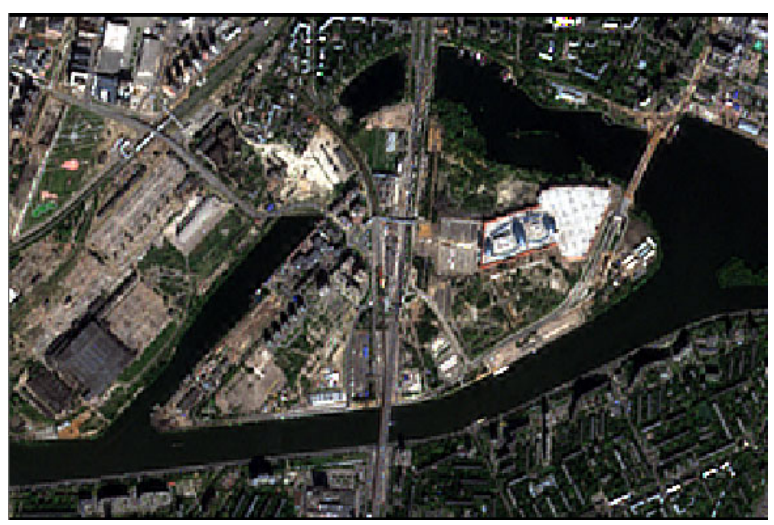

б)

Рис. 2. Парк развлечений «Остров мечты» на снимках Sentinel-2:

а) 18.09 .2015 ; б) 28.08.2019

Особенность изображений городской инфраструктуры характеризуется тем, что включает в себя объекты различной сложности, поэтому для правильной интерпретации данных необходимы, во-первых, снимки высокого разрешения, вовторых, хорошо работающие методики, использующие различные алгоритмы.

Выявить изменения по разновременным снимкам можно используя различные подходы. Один из них заключается в раздельной обработке исходных либо преобразованных изображений для их поэлементного сравнения с помощью встроенной опции ChangeDetection.

В данной работе для выявления произошедших изменений был использован метод, основанный на поэлементном сравнении индексных изображений. Значения яркости каждого пикселя такого изображения определяется путем применения арифметических операций над значениями яркости этого пиксела из разных каналов снимка. Индексные разновременные изображения представлены на рис. 3.

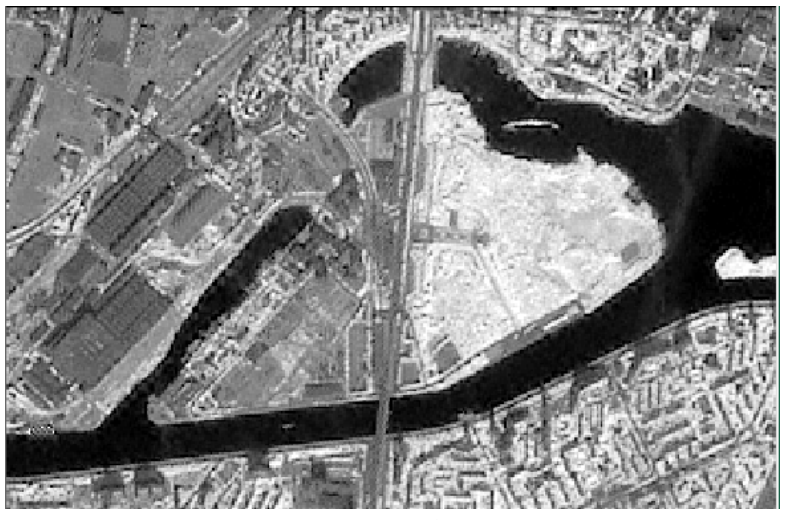

a)

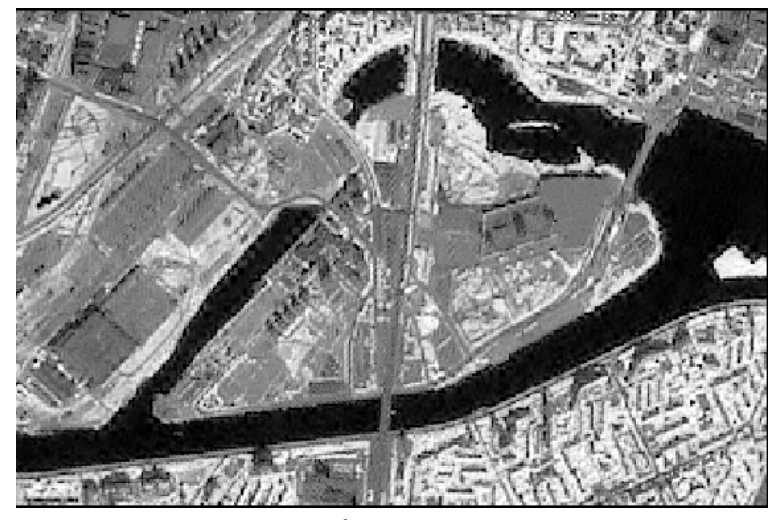

б)

Рис. 3. Индексные разновременные изображения:

a) 18.09 .2015 ; б) 28.08 .2019 
После выполнения преобразований изображений, полученных на разные даты, вычислялись разности для каждого канала. Путем экспериментов для каждой пары разновременных снимков были определены пороговые значения. Результат маски представлен на рис. 4.
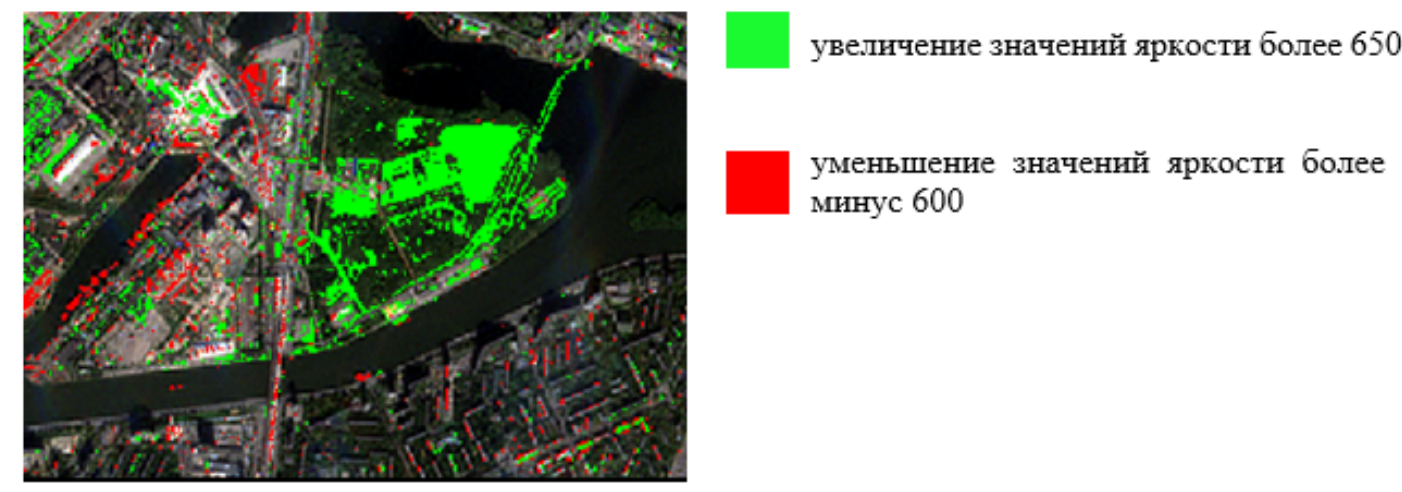

Рис. 4. Результаты выявления изменений между датами 18.09.2015 и 28.08.2019 методом, основанным на использовании индексных изображений

На полученном снимке отчетливо выделяются изменения появившиеся в результате строительства объектов, на нем можно наблюдать ложные изменения, вызванные различными факторами. К ним относятся: разные условия съемки, которые выражаются в изменении конфигурации теней на снимках, различные углы наклона снимков и положения точек надира приводят к наличию геометрических искажений, влекущие за собой выявление фиктивных изменений.

Анализ полученных результатов исследований показал, что алгоритмы автоматизированного выявления изменений в условиях городской застройки не всегда дают стабильно высокие результаты. Это связано с большим количеством «мешающих» факторов, затрудняющих автоматический анализ снимков. В связи с этим встает необходимость в разработке новых более сложных методик и алгоритмов для выявления произошедших изменений.

Можно выделить ряд преимуществ и недостатков использования снимков высокого разрешения при мониторинге объектов городской территории.

К достоинствам относится:

- высокая оперативность;

- доступность (возможность получения с бесплатных ресурсов);

- высокая периодичность съемки (1 раз в 5 (10) дней).

Недостаток же заключается в недостаточной разрешающей способности снимков для структурно сложных площадных объектов.

Таким образом, для облегчения поиска произошедших изменений на снимках, целесообразно использование, во-первых, снимков сверхвысокого разрешения, во-вторых, методик, комплексных критериев и решающих правил для совместного использования яркостных и структурных признаков. 


\section{БИБЛИОГРАФИЧЕСКИЙ СПИСОК}

1. Гук А. П., Евстратова Л. Г. Фотограмметрическая обработка многоспектральных аэрокосмических снимков при мониторинге территорий // Геодезия, Картография, Геоинформатика и Кадастры. От идеи до внедрения. II Международная научно-практическая конференция. - Политехника СПб, 2017. - С. 136-142.

2. Гордиенко, А. С. Применение индексных изображений при выявлении изменений по разновременным космическим снимкам // ИНТЕРЭКСПО ГЕО-СИБИРЬ. - 2015. - №1 - - с. 67-70.

3. Плотникова М. А., Хлебникова Е. П. Мониторинг городской территории по материалам космических съемок // Интерэкспо ГЕО-Сибирь. XVМеждунар. науч. конгр., 24-26 апреля 2019 г., Новосибирск : сб. материалов в 9 т. Т.6 : Магистерская научная сессия «Первые шаги в науке». - Новосибирск : СГУГиТ, 2019.№1 - С. 84-89.

4. Солонько Е. В., Хлебникова Е. П. Использование разновременных космических снимков для оценки развития оползневых процессов на территории города Барнаула // Интерэкспо ГЕО-Сибирь-2016. ХII Междунар. науч. конгр., 18-22 апреля 2016 г., Новосибирск : Магистерская научная сессия «Первые шаги в науке» : сб. материалов. - Новосибирск : СГУГиТ, 2016. C. $156-161$.

5. Хлебникова Е. П., Абишева М. Т. Особенности обнаружения изменений инженернотехнических сооружений при интерпретации и анализе космических изображений // Интерэкспо ГЕО-Сибирь-2016. ХІІ Междунар. науч. конгр., 18-22 апреля 2016 г., Новосибирск :Междунар. науч. конф. «Дистанционные методы зондирования Земли и фотограмметрия, мониторинг окружающей среды, геоэкология» : сб. материалов в 2 т. - Новосибирск : СГУГиТ, 2016. - T. 1. - C. 9-14.

6. Парк «Остров Мечты» [Электронный ресурс]. - Режим доступа: https://stroi.mos.ru/renovaciya-promzon/nagatinskii-zaton/kakim-stanet-nagatinskii-zaton/park-ostrovmiechty. - Загл. с экрана.

7. Дворкин, Б. А. Европейская программа GMES и перспективная группировка спутников Д33 Sentinel // Геоматика. - 2011. - No3 - С.14 -26.

(C) М. А. Плотникова, Е. П. Хлебникова, 2021 